\title{
Using WDS to Estimate the Firing Time of Koryŏ Celadons
}

\author{
Hyojin Lee, Gerald Wynick, and William Carty
}

New York State College of Ceramics at Alfred University, Alfred, NY 14802

Koryŏ period (918-1392 CE) Celadons are widely considered to be aesthetic masterpieces of ancient ceramics [1]. To create similar contemporary examples requires the glaze chemistry and proposed firing conditions (temperature and time). The measurement of the glaze chemistry from a glaze chip ignores the body-glaze interactions during firing [2] that drastically alter the glaze chemistry. Determining the extent of the body-glaze interactions solves both the time problem and the glaze chemistry problem, improving the potential to develop glazes with similar aesthetics to Koryŏ period celadons.

We were provided with several Koryŏ period celadon specimens (shards) and an exquisite $12^{\text {th }}$ century tea bowl from which we extracted a specimen (via core drill) for analysis. (Shard analysis is problematic, as kiln site shards are decidedly reject pieces, so these are ignored in this work.) The coredrilled specimen was mounted in epoxy and polished perpendicular to the body-glaze interface and not etched. Wavelength Dispersive Spectroscopy (WDS) was used to map the body-glaze interface using a JEOL Model JXA-8200, operating at $10 \mathrm{keV}$, spot diameter of $1 \mu \mathrm{m}$, and beam current of $0.03 \mu \mathrm{A}$. As shown in Figure 1, the overall glaze thickness is $\sim 390 \mu \mathrm{m}$. The original body-glaze interface location is necessary to determine body-glaze interaction depth. Comparison of the $\mathrm{Si}$ and $\mathrm{Al}$ scans indicated mullite $\left(3 \mathrm{Al}_{2} \mathrm{O}_{3} \cdot 2 \mathrm{SiO}_{2}\right)$ in the glaze. Mullite, however, is not a possible reaction product in glaze melting and only precipitates in the body during firing [3]. Since Koryŏ celadons are single-fired products, mullite could only be present in the glaze if it was present in the body prior to firing - previously fired ware was crushed and incorporated into the new body as grog. As the glaze dissolves the body during firing, the mullite particles, which are insoluble in the glaze, remain suspended in the glaze, providing the location of the original body-glaze interface. The body-glaze interaction depth was $\sim 230 \mu \mathrm{m}-4 \mathrm{x}$ greater than typically observed for contemporary glaze systems [4].

To determine the time necessary to obtain a body-glaze interaction depth, a series of glazed samples were prepared and fired for various times at $1250^{\circ} \mathrm{C}$ and $1300^{\circ} \mathrm{C}$ [5]. The original body-glaze interface was marked by adding zircon into the body (which is insoluble in the glaze). The results produced three observations (Figure 2): (1) body-glaze interaction depth is $\log$-log with time; (2) single-fire and twice fired systems have similar body-glaze interaction behavior; and (3) similar depth versus time results at $1250^{\circ} \mathrm{C}$ and $1300^{\circ} \mathrm{C}$. Other work on the Koryŏ celadon specimen involving the glass composition in the celadon body indicated a peak firing temperature of $1250^{\circ} \mathrm{C}$ [6]. The extent of the body-glaze interaction indicated that the tea bowl had been held at peak temperature for $\sim 100$ hours ( 4 days \pm 1 day).

Such a long firing cycle partially explains the aesthetics of the Koryŏ period glazes and the difficulties in duplicating these glazes. Finally, it is evident from the WDS data, that the iron level in the glaze is identical to that in the body - iron provides the glaze with its characteristic green color, and does not appear to be an initial glaze component but a result of body-glaze interactions. 
References:

[1] P. VanDiver, Radiance of Jade and the Clarity of Water, 151-158, Art Inst. of Chicago, 1991.

[2] N. Wood, Chinese Glazes, pp. 40 and 268, 1999

[3] B. Quinlan, M.S. Thesis, Alfred University, 2002

[4] D. Finkelnburg, M.S. Thesis, Alfred University, 2006.

[5] T. Rein, B.S. Thesis, Alfred University, 2010.

[6] R. Ouyang, M.S. Thesis, Alfred University, 2015.
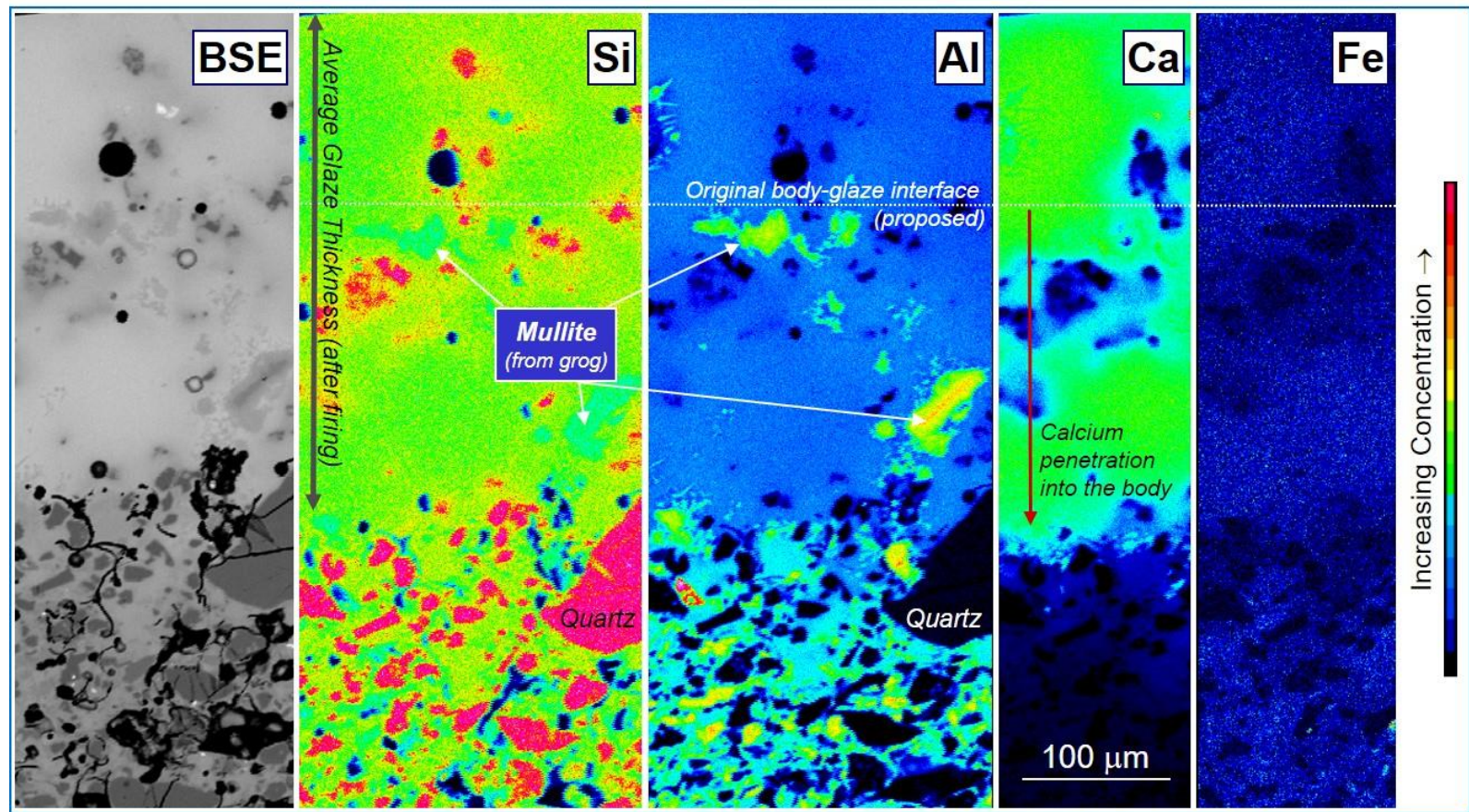

Figure 1. A back-scatter image and WDS-generated chemical maps of the body-glaze cross-section of a Koryo Dynasty celadon. The presence of mullite, evident in the Si and Al images, indicates the original body-glaze interface and showing the depth of body-glaze interaction during firing.

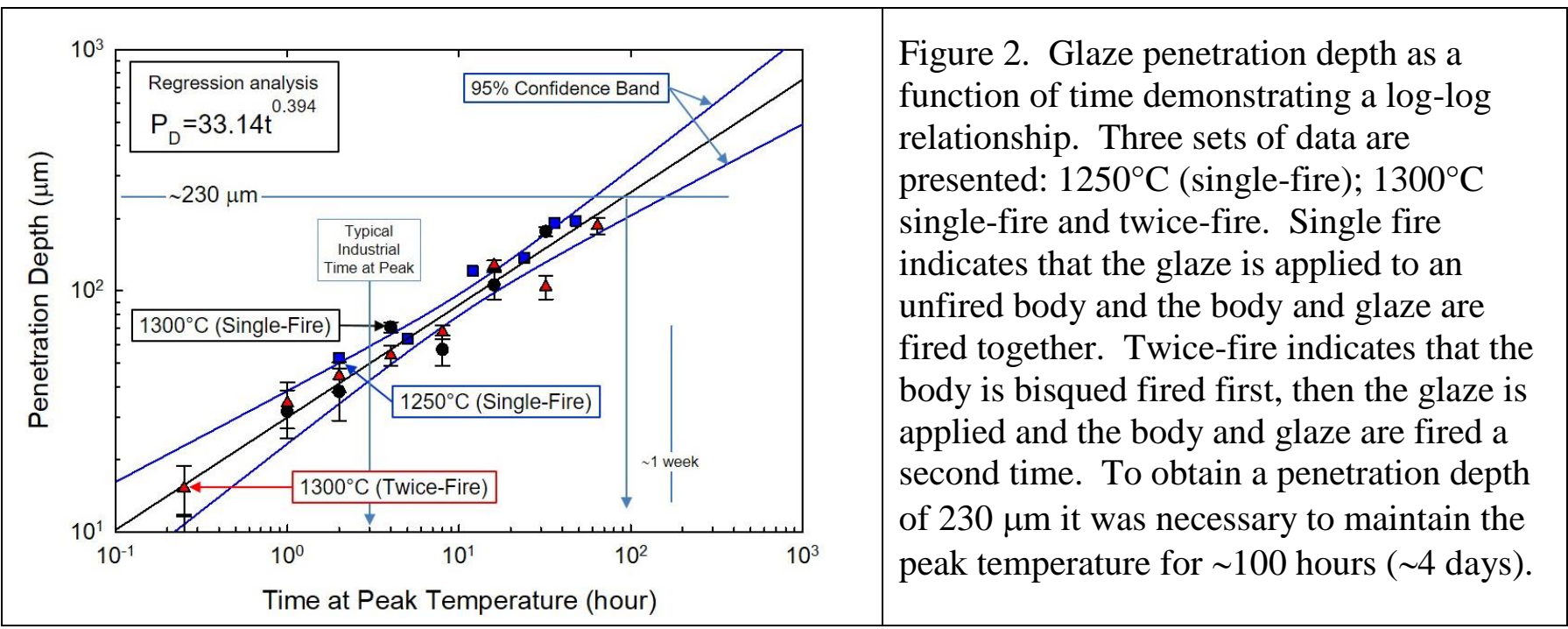

